\title{
On the Machinability and Surface Finish of Superalloy GH909 Under Dry Cutting Conditions
}

\author{
Ming $\operatorname{Luo}^{a *} *^{0}$, Haizhen $\mathrm{Li}^{a}$ \\ ${ }^{a}$ Key Laboratory of Contemporary Design and Integrated Manufacturing Technology, Northwestern \\ Polytechnical University, Ministry of Education, Xi'an 710072, China
}

Received: December 12, 2017; Revised: February 27, 2018; Accepted: April 15, 2018

\begin{abstract}
GH 909 alloy is a kind of low thermal expansion superalloy with high strength and low expansion coefficient. It is mainly used for manufacturing of aero-engine turbine casings, sealing ring, vanes and other gap control parts, to improve the working efficiency and thrust of the engine as well as to reduce gas loss and fuel consumption. However, the machinability is still a problem that restricts the application of GH909. This paper investigated the machinability referring to cutting forces, surface quality and tool wear in the milling process with carbide tool. The main conclusions are: (1) GH909 has similar machinability with other Nickel-based alloys, cutting velocity does not have great influence on cutting forces for small radial cutting depth. (2) Good machined surface quality can be get for cutting velocity around $70 \mathrm{~m} / \mathrm{min}$. (3) To get good tool performance and reduce tool wear rate, cutting velocity can be set to no larger than $80 \mathrm{~m} / \mathrm{min}$.
\end{abstract}

Keywords: machinability, surface finish, cutting force, tool wear, superalloy.

\section{Introduction}

GH 909 alloy is Fe-Ni-Co-based low thermal expansion superalloy, it has high strength, low expansion coefficient, almost constant modulus of elasticity under temperature below $650^{\circ} \mathrm{C}$. GH909 alloy is mainly used for manufacturing of aero-engine turbine casings, sealing ring, vanes and other gap control parts. The application of GH909 alloy can improve the working efficiency and thrust of the engine, and can reduce gas loss as well as fuel consumption. While used for manufacturing of aero-engine parts, machining of these parts either by turning or by milling is required. However, the published research is mainly about machining of Ni-based alloy 718 , the machinability of alloy 909 is rarely studied. Motivated by the above analysis and requirements, the machinability of alloy 909 is studied in this paper.

The machinability of materials refers to the ease with which a metal can be machined permitting the removal with satisfactory finish at low cost. The machinability of superalloys is not only related with material property, but also affected by the machining condition. For superalloys such as GH909 and In718, their machinability is low, it means they are difficult to cut. Machinability of Nickel-based alloys has been studied, such as Inconel $718^{1,2}, \mathrm{GH} 2132^{3}$ and so on. However, seldom research has been focused on the machinability of superalloy GH909, it leads to the confusion of selection proper cutting parameters for machining process. Like other Nickel-based alloys, GH909 is difficult to cut, the cutting force and temperature are very high during the machining process, resulting in fast tool wear and poor surface finish.
Cutting force is one of the main factors that reflect the ease of metal cutting, lots of research has been done to investigate the effects of cutting parameters on cutting forces ${ }^{4,5}$. While machining Inconel 718, Choudhury and El-Baradie ${ }^{6}$ found that the cutting forces did not decrease because of higher shear stress. Experiments conducted by Devillez et al. ${ }^{7}$ showed that cutting forces in wet and dry turning of Inconel 718 were almost the same and the cutting force was a bit lower at cutting speed of $60 \mathrm{~m} / \mathrm{min}$. In side milling of Inconel 718, Liao et al. ${ }^{8}$ found that cutting force did not change a lot within the cutting speed $20-120 \mathrm{~m} / \mathrm{min}$, while it showed increase for cutting speed larger than $120 \mathrm{~m} / \mathrm{min}$. Nalbant et al. ${ }^{9}$ studied the effect of cutting speed on cutting forces in milling of Inconel 718 with ceramic cutting tools, they found an incrementdecrement relationship between cutting speed and cutting force within $150-250 \mathrm{~m} / \mathrm{min}$. While machining Inconel alloy 738, Davoodi and Tazehkandi ${ }^{10}$ found that the depth of cut has the most effective on cutting forces, followed by feed rate and cutting speed, and increasing cutting speed at permitted range caused softening and elastic deformation in cutting region and resulted in reduction of cutting forces. They also found the increase of cutting force when the cutting speed is larger than a certain value. From the existing research results it can be found that cutting forces do notchange a lot with increase of cutting speed within certain range, while the cutting speed is much larger, the cutting forces show an increment with increase of cutting speed. Among all the machining parameters, cutting depth has the most effective on cutting forces.

Tool wear is one of the main concern in the machining process, it affects the dimension accuracy ${ }^{11}$, 
machined surface integrity ${ }^{12}$, and machining stability ${ }^{13}$. Choudhury and El-Baradie ${ }^{6}$ found that cutting speed has more effect than cutting depth and feed rate on tool life. While machining Inconel 718 with ceramic cutting tools, research shows that the main tool wear mechanism are crater, tool breakage, and notch wear ${ }^{9}$. Sikdar's ${ }^{14}$ research showed that different wear mechanism occurred for ceramic tools under various cutting conditions and micro chipping occurred at high feed rates. Henderson et al. ${ }^{15}$ investigated the cutting forces in milling of Nickelbased superalloys, their experimental results indicated that the cutting speed has a significant influence on the amplitude of forces and tool wear rate. Li et al. ${ }^{16}$ studied the end milling of Inconel 718 using coated carbide inserts under dry cutting conditions, their experiments showed that significant flank wear was the predominant failure mode. Krain et al. ${ }^{17}$ conducted experiments on milling of Inconel $718 \mathrm{TM}$ and results showed that increase of immersion ratio resulted in reduction of tool life due to increased cutting length, abrasion rates, thermal and mechanical loads. Yao et al. ${ }^{18}$ found that the use of different cutter orientations have significant effects on the tool life, workpiece surface integrity and surface morphology. Hao et al. ${ }^{19}$ analyzed the tool wear morphology and mechanism in dry machining of Inconel 718, and they found that adhesion and lamellar wear caused tool wear at low cutting speed $20 \mathrm{~m} / \mathrm{min}$, while the element diffusion between tool and workpiece and oxidation reaction all accelerate the formation and peeling of wear debris. While turning N-155 iron-nickelbase superalloy, Davoodi and Eskandari ${ }^{20}$ found that cutting speed was the most significant factor and the most dominant tool failure modes were adhesion wear. During dry machining of Inconel 825, Thakur et al. ${ }^{21}$ et al. found the dominating tool wear mechanism were abrasion, adhesion, and diffusion wears. Zhu et al. ${ }^{22}$ concluded that the actual wear rate is the combination of adhesion, abrasion, diffusion, and oxidation wear rate in cutting of Nickel-based alloy, depending on the temperature and stress distributions. However, tool wear mechanism for the machining of GH909 is still unclear and lack of investigation.

Surface finish reflects the machined surface quality ${ }^{23}$, it will influence the component service life. Both cutting parameters and cutter geometry ${ }^{24}$ will affect the final machined surface finish. Furthermore, tool wear in the machining process will have great influence on the machined surface finish. Sonawane and Joshi ${ }^{25}$ investigated the effect of machining parameters on the machined surface quality in a single-pass of a ball-end milling cutter, and results showed that the maximum surface roughness is observed near the tool tip region on the machined surface. Sikdar's ${ }^{14}$ research showed that the quality of the machined surface was better at high cutting speeds than that at low speed, under which condition the surface was full of short grooves with high feed rate. In turning of Inconel 718, Devillez et al. ${ }^{7}$ found that the cutting speed of $60 \mathrm{~m} / \mathrm{min}$ in dry condition with coated tool can get globally optimized surface finish quality. Davoodi and Tazehkandi ${ }^{10}$ found that the most effective parameter on surface roughness was feed rate, and higher cutting speed with lower feed rates can be used for getting lower surface roughness in machining of Inconel 738. Tazehkandi et al. ${ }^{26}$ recommended the cutting speed should not exceed $80 \mathrm{~m} / \mathrm{min}$ while machining Inconel 725 to avoid deterioration of surface finish, and there was a general trend of increasing of cutting forces as feed rate and cutting depth increase. Current research show that higher cutting speed with low feed rate can get good surface finish for machining of Nickelbased alloy. Choudhury and El-Baradie ${ }^{6}$ recommended the cutting speed for machining Inconel 718 using the carbide inserts should be within $20-25 \mathrm{~m} / \mathrm{min}$. Krain et al. ${ }^{17}$ indicated that while milling Inconel $718 \mathrm{TM}$, the immersion ratio can be set as $50 \%$ and the chip thickness of $0.1 \mathrm{~mm}$. Liao et al ${ }^{8}$ suggested that cutting speed of $90-110 \mathrm{~m} / \mathrm{min}$ is appropriate for slot milling of Inconel 718 and $55-135 \mathrm{~m} / \mathrm{min}$ for side milling.

Notwithstanding the aforementioned various studies proposed therein, none of them studied the machinability of GH909 alloy. Therefore, this paper investigated the machinability referring to cutting forces, surface quality and tool wear in the milling process with carbide tool. Finally, the recommended cutting parameters for milling GH909 alloy are given based on the machinability analysis.

\section{Experiments}

\subsection{Material}

The chemical composition (wt\%) of the GH909 alloy is shown in Table 1 , the containing of Niobium and Titanium components are used for precipitation hardening, the silicon addition results in improved notch rupture and tensile properties. Some physicalproperties of GH909 are listed in Table 2. The rigidity and the modulus of elasticity of GH909 alloy remains nearly constant over a wide temperature range. Due to its low expansion andconstant elastic modulus, GH909 alloy has highly resistant to thermal fatigueand thermal shock.

Table 1. Chemical composition of the alloy GH909.

\begin{tabular}{ccccccccccccccc}
\hline $\mathrm{C}$ & $\mathrm{Mn}$ & $\mathrm{Si}$ & $\mathrm{Ni}$ & $\mathrm{Co}$ & $\mathrm{Al}$ & $\mathrm{Ti}$ & $\mathrm{Nb}$ & $\mathrm{Cr}$ & $\mathrm{B}$ & $\mathrm{Cu}$ & $\mathrm{P}$ & $\mathrm{S}$ & $\mathrm{Y}$ & $\mathrm{Fe}$ \\
\hline 0.01 & $<0.20$ & 0.42 & 38.41 & 13.08 & 0.10 & 1.41 & 4.76 & $<0.05$ & 0.006 & $<0.10$ & $<0.01$ & 0.004 & $<0.005$ & Balance \\
\hline
\end{tabular}


Table 2. .Physical properties of alloy GH909.

\begin{tabular}{lccc}
\hline Density $\left(\mathrm{g} / \mathrm{cm}^{3}\right)$ & Melting range $\left({ }^{\circ} \mathrm{C}\right)$ & $\mathrm{W}_{5}(\%)$ & $\mathrm{j}(\%)$ \\
\hline 8.19 & 1400 & 16 & 47 \\
\hline
\end{tabular}

\subsection{Experimental setup}

The experimental were carried out on a four-axis machining center YHVT 850Z, the cutting tool used for cutting forces and roughness investigation is coated carbide milling cutter with four flutes and its diameter is $10 \mathrm{~mm}$, and the diameter for tool wear investigation is $12 \mathrm{~mm}$. Three groups of experiments were conducted: cutting with large radial depth, cutting with large axial depth and tool wear experiments. The cutting experiments are given from Table 3 to Table 5. Two machining processes: end milling and flank milling, are commonly used in the workshop. The cutting experiments with large radial cutting depth simulates the end milling process, and the cutting experiments with large axial cutting depth simulates the flank milling process. The milling experiment setup is shown in Figure 1, the stock length is $120 \mathrm{~mm}$. Referring to machining of hard-to-cut materials, radial depth of cut is usually set to small value, such as below $1.0 \mathrm{~mm}$, to avoid large cutting force or high cutting temperature and to reduce tool wear rate. Therefore, while setting the radial cutting depth to $4.0 \mathrm{~mm}$, it is relatively large value.

Table 3. Cutting experiments with large radial depth.

\begin{tabular}{lccc}
\hline $\begin{array}{l}\text { Cutting velocity } \\
(v, \mathrm{~m} / \mathrm{min})\end{array}$ & $\begin{array}{c}\text { Feed per tooth } \\
\left(f_{\mathrm{z}}, \mathrm{mm} / \mathrm{tooth}\right)\end{array}$ & $\begin{array}{c}\text { Axial } \\
\text { depth of } \\
\text { cut } \\
\left(a_{\mathrm{p}}, \mathrm{mm}\right)\end{array}$ & $\begin{array}{c}\text { Radial depth } \\
\text { of cut } \\
\left(a_{\mathrm{e}}, \mathrm{mm}\right)\end{array}$ \\
\hline 50 & 0.015 & & \\
65 & 0.020 & & \\
80 & 0.025 & 1.5 & 4.0 \\
95 & 0.030 & & \\
110 & 0.035 & & \\
\hline
\end{tabular}

Table 4. Cutting experiments with large axial depth.

\begin{tabular}{lccc}
\hline $\begin{array}{l}\text { Cutting velocity } \\
(v, \mathrm{~m} / \mathrm{min})\end{array}$ & $\begin{array}{c}\text { Feed per tooth } \\
\left(f_{\mathrm{z}}, \mathrm{mm} / \mathrm{tooth}\right)\end{array}$ & $\begin{array}{c}\text { Axial depth } \\
\text { of cut } \\
\left(a_{\mathrm{p}}, \mathrm{mm}\right)\end{array}$ & $\begin{array}{c}\text { Radial } \\
\text { depth of cut } \\
\left(a_{\mathrm{e}}, \mathrm{mm}\right)\end{array}$ \\
\hline 50 & 0.020 & & \\
70 & 0.035 & 6.0 & 0.5 \\
90 & 0.050 & & \\
110 & 0.065 & & \\
\hline
\end{tabular}

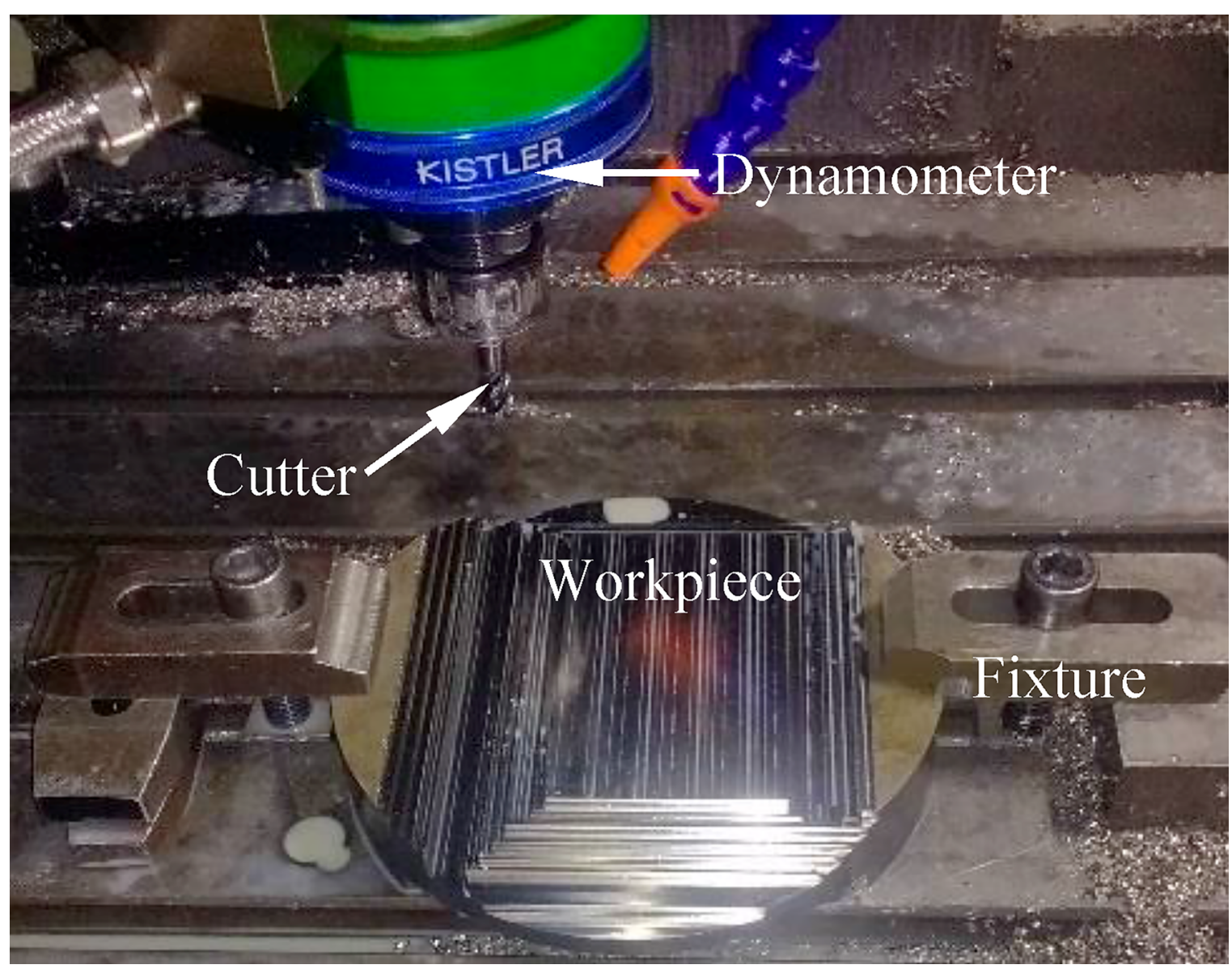

Figure 1. Milling experimental setup. 
Table 5. Cutting parameters for tool wear experiments.

\begin{tabular}{lcccc}
\hline No. & $\begin{array}{c}\text { Cutting } \\
\text { velocity } \\
(v, \mathrm{~m} / \mathrm{min})\end{array}$ & $\begin{array}{c}\text { Feed per tooth } \\
\left(f_{\mathrm{z}}, \mathrm{mm} / \text { tooth }\right)\end{array}$ & $\begin{array}{c}\text { Axial depth } \\
\text { of cut } \\
\left(a_{\mathrm{p}}, \mathrm{mm}\right)\end{array}$ & $\begin{array}{c}\text { Radial depth } \\
\text { of cut } \\
\left(a_{\mathrm{e}}, \mathrm{mm}\right)\end{array}$ \\
\hline 1 & 50 & 0.025 & & \\
2 & 50 & 0.035 & & \\
3 & 80 & 0.015 & & \\
4 & 80 & 0.025 & 1.5 & 4.0 \\
5 & 80 & 0.035 & & \\
6 & 110 & 0.015 & & \\
7 & 110 & 0.025 & & \\
8 & 110 & 0.035 & & \\
\hline
\end{tabular}

\subsection{Measurement}

Cutting force, tool wear and surface finish are the key indexes for machinability evaluation. In this study, cutting forces during the milling process were measured by the Kistler $9123 \mathrm{C}$ dynamometer, cutting forces along radial, tangential and axial directions were recorded. Tool wear and machined surface roughness were measured by the Alicona G4 3D micro coordinate measurement machine, and the measured scope range is $200 \mu \mathrm{m} * 200 \mu \mathrm{m}$.

\section{Results and Discussion}

\subsection{Cutting force}

Regarding milling with large radial cutting depth and low axial cutting depth, variation of resultant cutting force with cutting velocity and feed per tooth is shown in Figure 2. With the increase of feed per tooth, cutting force shows increasing trend. As for the influence of cutting velocity, the cutting force shows increase trend for cutting velocity smaller than $80 \mathrm{~m} / \mathrm{min}$, but there is a decrease after $80 \mathrm{~m} / \mathrm{min}$ for feed per tooth larger than $0.02 \mathrm{~mm} /$ tooth. Results for large axial cutting depth and small radial cutting depth are shown in Figure 3. For Nickel-based alloys like Inconel 718, research results show that the cutting forces do not show obvious change with the increase of cutting velocity within a certain range. In this research, the same trend is found for small radial cutting depth while there is a discrepancy for large radial cutting depth with different feed per tooth. For feed per tooth smaller than $0.02 \mathrm{~mm} /$ tooth, the trend is almost the same, but for those larger than $0.025 \mathrm{~mm} /$ tooth, cutting forces shows increase trend for cutting velocity smaller than $80 \mathrm{~m} / \mathrm{min}$. For milling process with large axial cutting depth and small radial cutting depth, the cutting forces show slow increase trend with cutting velocity. Comparing forces with large radial cutting depth, cutting forces show an interesting dramatic increase with cutting velocity under large feed per tooth, while this phenomenon is not observed under the situation with small radial cutting depth.

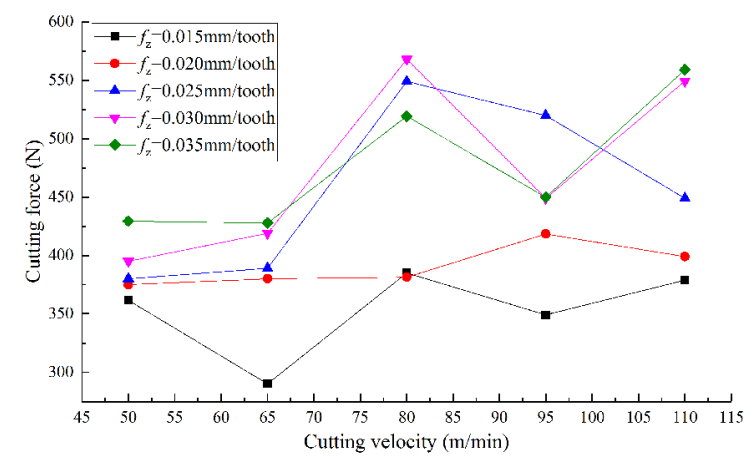

Figure 2. Resultant cutting force with large radial cutting depth and low axial cutting depth

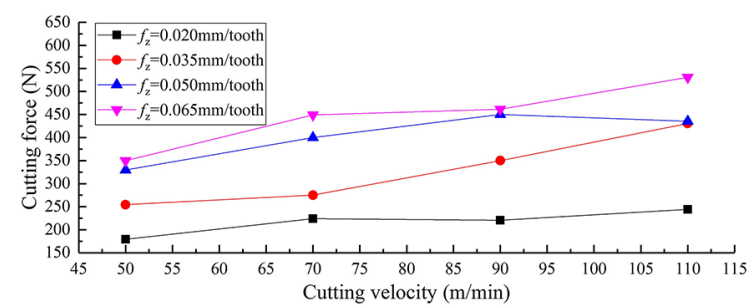

Figure 3. Resultant cutting force with large axial cutting depth and small radial cutting depth

Although the feed per tooth is set to much larger value for large axial cutting experiments, the maximum actual undeformed chip thickness is almost the same as that for large radial cutting experiments, it is smaller than the value of feed per tooth, as shown in Figure 4. For example, the maximum actual undeformed chip thickness is about $0.028 \mathrm{~mm}$ for feed per tooth at $0.065 \mathrm{~mm} /$ tooth. For both groups of experiments, it can be found that for the same cutting velocity, the large axial cutting depth approach can achieve the same material removal rate (MRR) with much larger feed per tooth, while the cutting force is almost the same. Take the cutting velocity at $65 \mathrm{~m} / \mathrm{min}$ of large radial cutting depth as example, the cutting force for feed per tooth at $0.025 \mathrm{~mm} / \mathrm{min}$ is about $390 \mathrm{~N}$. Meanwhile, for large axial cutting depth with cutting velocity as $70 \mathrm{~m} /$ $\mathrm{min}$, the cutting force for feed per tooth at $0.050 \mathrm{~mm} /$ tooth is about $400 \mathrm{~N}$. However, for large axial cutting depth and small radial cutting depth, the heating duration for each cutter flute is much shorter than large radial cutting depth situation, which means the working condition is much better for the cutter.

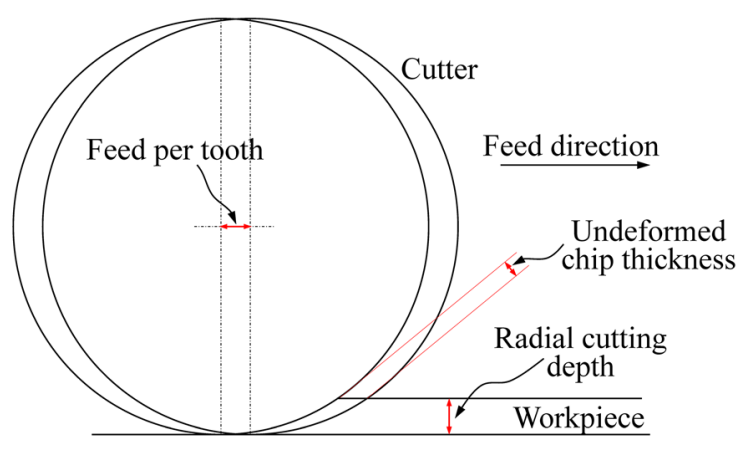

Figure 4. Undeformed chip thickness and feed per tooth 


\subsection{Surface quality}

For large radial cutting depth and small axial cutting depth, the influence of cutting velocity and feed per tooth on surface roughness is shown in Figure 5. There is no general trend of the surface roughness, but for some of them the surface roughness value reduces gradually with the cutting velocity. With the increase of feed per tooth, the main tendency is increase of the surface roughness.

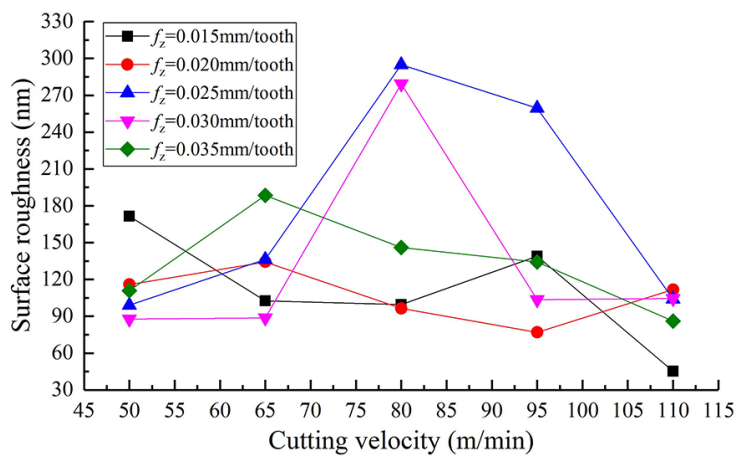

Figure 5. Influence of cutting velocity and feed per tooth on surface roughness for large radial cutting depth

For large axial cutting depth and small radial cutting depth, the surface roughness shows interesting similarity. The surface roughness value is low at cutting velocity of $70 \mathrm{~m} / \mathrm{min}$ for all feeds per tooth, while it is high at cutting velocity of $90 \mathrm{~m} / \mathrm{min}$. As for feed per tooth, larger value will not result inhigher surface roughness value, as shown in Figure 6.

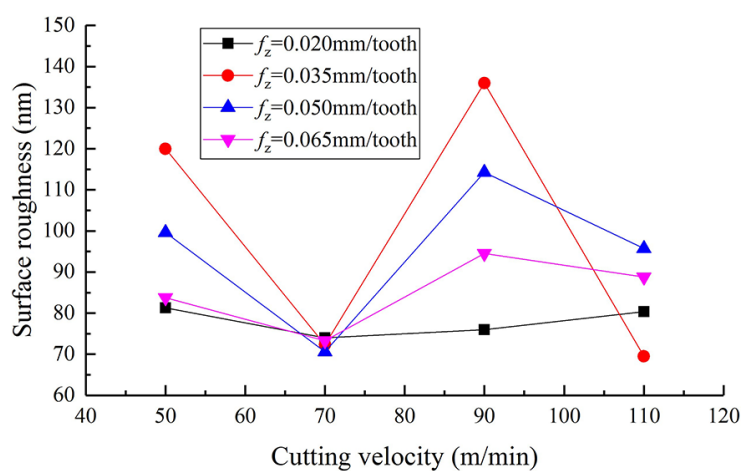

Figure 6. Influence of cutting velocity and feed per tooth on surface roughness for large axial cutting depth

The sampled surface texture is shown in Figure 7, the surface roughness is formed by the bottom edge of the milling cutter. From the surface texture, the chip breakage marks are obviously shown for feed per tooth $0.020 \mathrm{~mm} /$ tooth and $0.035 \mathrm{~mm} /$ tooth. The chip breakage period, which is the period between two neighboring chips breakage, does not show relevance with the cutting velocity. However, cutting length within one chip breakage period shows increase with the feed per tooth. As shown in Figure 7(a), the cutting length within one chip breakage period is about $70 \mu \mathrm{m}$ for feed per tooth of $0.020 \mathrm{~mm} /$ tooth, while it is about $138 \mu \mathrm{m}$ for feed per tooth of $0.035 \mathrm{~mm} /$ tooth and $195 \mu \mathrm{m}$ for feed per tooth of $0.05 \mathrm{~mm} /$ tooth. In the milling process, the path of the cutter edge tip is trochoid, the larger the feed, the greater the maximum radius of the trochoid. For small radius, the deformed chip tends to be compressed from both the rake face of the cutter and the cross-feed direction. For large radius, especially for straight cutting like orthogonal cutting, thedeformed chip is mainly compressed on the rake face of the cutter. Therefore, it reveals the influence of feed per tooth on chip breakage. Cross the chip breakage area, the surface roughness shows obvious variation, as shown in Figure 8.

\subsection{Tool wear}

Tool wear under different cutting conditions for the same type of milling cutter is shown in Figure 9. The low thermal conductivity of the GH909 alloy and the work hardening in the milling process cause elevated high temperature at the interface between the cutter and the workpiece. High temperature accelerates the welding and adhesion onto the cutting tool, which leads to the damage on the tool rake face. Besides, the adhesion and work hardening during the milling process lead to severe notching between the cutting edge and the machined surface, and induce flank wear. Due to the above reasons, the cutting edge is almost completely worn out. This phenomenon is obvious for cutting velocity less than $80 \mathrm{~m} / \mathrm{min}$. For cutting velocity larger than $80 \mathrm{~m} / \mathrm{min}$, chipping is observed as the main tool wear mode. As was explained in section 3.1, cutting forces increase slowly with the increase of cutting velocity, larger cutting forces accelerate the damage of cutting edge. For the cutting velocity of $80 \mathrm{~m} / \mathrm{min}$, cutter edge chipping is also observed for feed per tooth of $0.035 \mathrm{~mm} /$ tooth. From the above analysis, it can be concluded that for milling of GH909 alloy, the cutting velocity below $80 \mathrm{~m} / \mathrm{min}$ will have better tool performance.

\section{Conclusions}

In summary, GH909 alloy shows similar machinability as other Nickel-based alloys, such as In718. Based on the analysis of the results, conclusions can be drawn as follows for milling of GH909 alloy with carbide tools: 


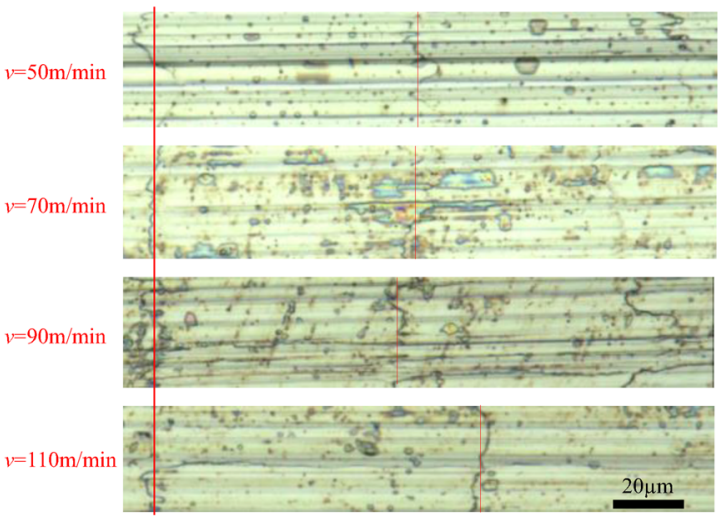

(a) $0.020 \mathrm{~mm} /$ tooth

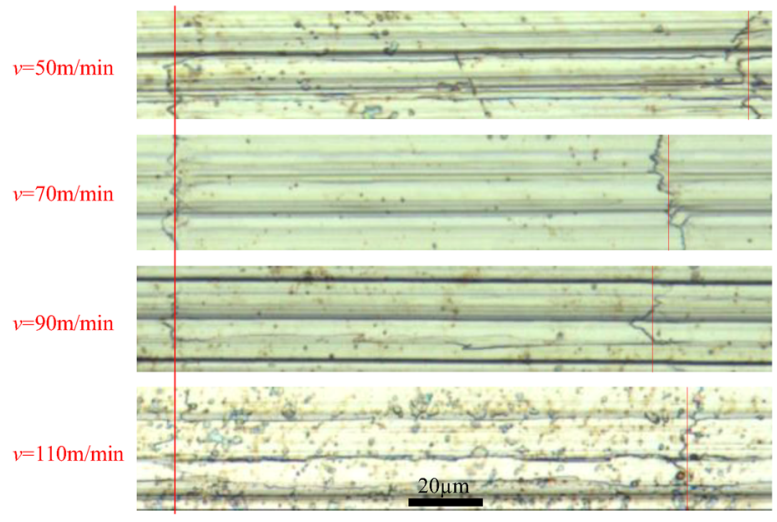

(b) $0.035 \mathrm{~mm} /$ tooth

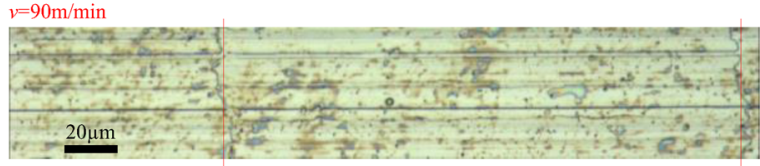

(c) $0.050 \mathrm{~mm} /$ tooth

Figure 7. Machined surface texture

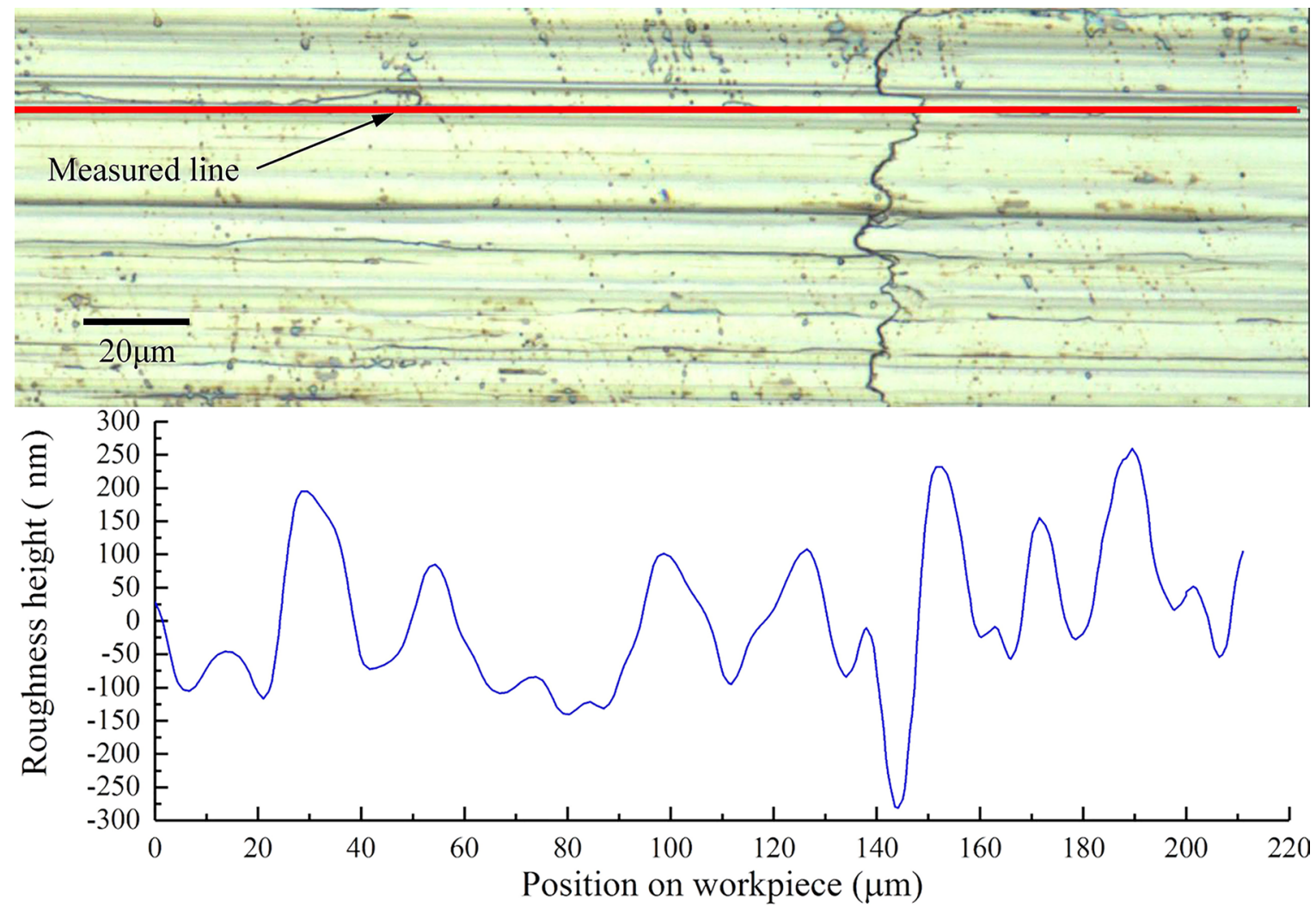

Figure 8. Surface roughness

1. Cutting force shows increasing trend with the increase of feed per tooth. For small radial cutting depth, cutting forces do not show obvious change with the increase of cutting velocity.
2. Within the experimental parameter range, the surface roughness value is low at cutting velocity of $70 \mathrm{~m} /$ min for different feeds per tooth. Feed per tooth has influence on chip breakage and larger feed per 


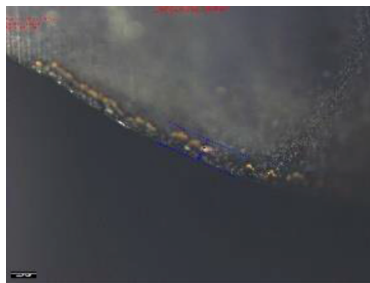

$v=50 \mathrm{~m} / \mathrm{min}$ $f_{\mathrm{z}}=0.025 \mathrm{~mm} /$ tooth

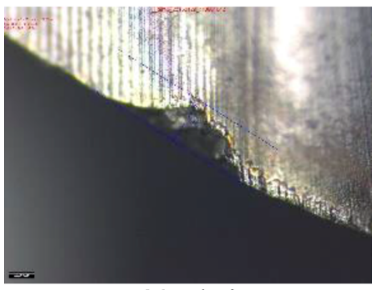

$v=80 \mathrm{~m} / \mathrm{min}$ $f_{\mathrm{z}}=0.035 \mathrm{~mm} /$ tooth

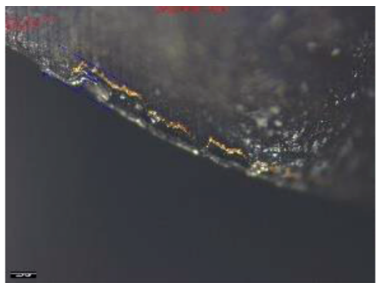

$v=50 \mathrm{~m} / \mathrm{min}$

$f_{\mathrm{z}}=0.035 \mathrm{~mm} /$ tooth

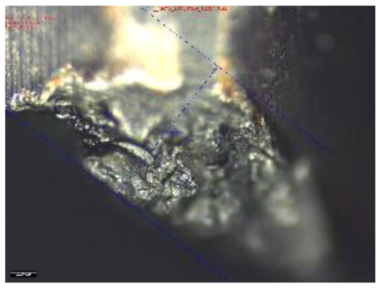

$v=110 \mathrm{~m} / \mathrm{min}$

$f_{\mathrm{z}}=0.015 \mathrm{~mm} /$ tooth

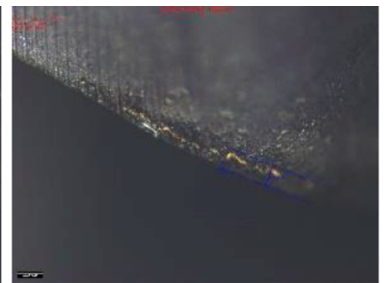

$v=80 \mathrm{~m} / \mathrm{min}$

$f_{\mathrm{z}}=0.015 \mathrm{~mm} /$ tooth

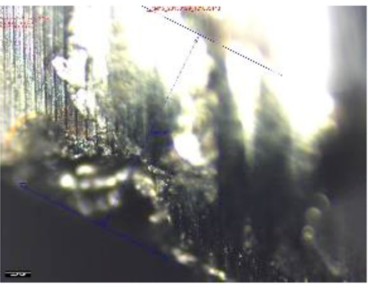

$v=110 \mathrm{~m} / \mathrm{min}$ $f_{\mathrm{z}}=0.025 \mathrm{~mm} /$ tooth

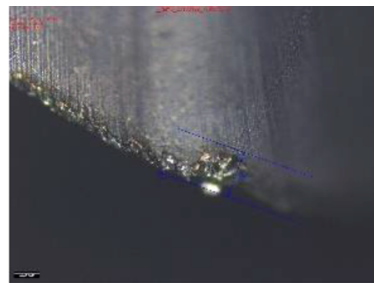

$v=80 \mathrm{~m} / \mathrm{min}$ $f_{\mathrm{z}}=0.025 \mathrm{~mm} /$ tooth

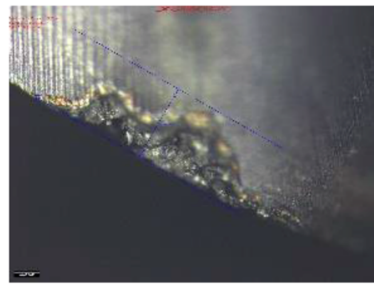

$v=110 \mathrm{~m} / \mathrm{min}$ $f_{\mathrm{z}}=0.035 \mathrm{~mm} /$ tooth

Figure 9. Tool wear under different cutting parameters (flank edge)

tooth results in longer chip breakage period, cutting velocity does not show clear relevance with chip breakage period.

3. To get better tool performance in milling of GH909 alloy, the cutting velocity should be set smaller than $80 \mathrm{~m} / \mathrm{min}$.

4. In summary, the cutting velocity for milling of GH909 can be set to around $70 \mathrm{~m} / \mathrm{min}$ and no larger than $80 \mathrm{~m} / \mathrm{min}$, and small radial cutting depth can be used to get good cutter working condition. For further research, surface integrity in milling of GH909 can be investigated to fulfil the requirements of components service performance.

\section{Acknowledgments}

This work was co-supported by the National Natural Science Foundation of China (51675438) and the Fundamental Research Funds for the Central Universities (No. 3102017gx06008).

\section{References}

1. Arunachalam R, Mannan MA. Machinability of nickel-based high temperature alloys. Machining Science and Technology. 2000;4(1):127-168.

2. Luo M, Luo H, Zhang D, Tang K. Improving tool life in multiaxis milling of Ni-based superalloy with ball-end cutter based on the active cutting edge shift strategy. Journal of Materials Processing Technology. 2018;252:105-115.

3. Wang X, Huang C, Zou B, Liu H, Zhu H, Wang J. A new method to evaluate the machinability of difficult-to-cut materials. The International Journal of Advanced Manufacturing Technology. 2014;75(1-4):91-96.
4. Wan M, Ma YC, Feng J, Zhang WH. Study of static and dynamic ploughing mechanisms by establishing generalized model with static milling forces. International Journal of Mechanical Sciences. 2016;114:120-131.

5. Sui S, Li Y, Shao W, Feng P. Tool path generation and optimization method for pocket flank milling of aircraft structural parts based on the constraints of cutting force and dynamic characteristics of machine tools. The International Journal of Advanced Manufacturing Technology. 2015;85(5-8):1553-1564.

6. Choudhury IA, El-Baradie MA. Machining nickel base superalloys: Inconel 718. Journal of Engineering Manufacture. 1998;212(3):195-206.

7. Devillez A, Le Coz G, Dominiak S, Dudzinski D. Dry machining of Inconel 718, workpiece surface integrity. Journal of Materials Processing Technology. 2011;211(10):1590-1598.

8. Liao YS, Lin HM, Wang JH. Behaviors of end milling Inconel 718 superalloy by cemented carbide tools. Journal of Materials Processing Technology. 2008;201(1-3):460-465.

9. Nalbant M, Altin A, Gökkaya H. The effect of cutting speed and cutting tool geometry on machinability properties of nickel-base Inconel 718 super alloys. Materials \& Design. 2007;28(4):1334-1338.

10. Davoodi B, Hosseini Tazehkandi A. Cutting forces and surface roughness in wet machining of Inconel alloy 738 with coated carbide tool. Proceedings of the Institution of Mechanical Engineers, Part B: Journal of Engineering Manufacture. 2014;230(2):215-226.

11. Luo M, Wang J, Wu B, Zhang D. Effects of cutting parameters on tool insert wear in end milling of titanium alloy Ti6A14V. Chinese Journal of Mechanical Engineering. 2017;30(1):53-59.

12. Stipkovic MA, Bordinassi EC, Farias A, Delijaicov S. Surface Integrity Analysis in Machining of Hardened AISI 4140 Steel. Materials Research. 2017;20(2):387-394. 
13. Yao Q, Luo M, Zhang D, Wu B. Identification of cutting force coefficients in machining process considering cutter vibration. Mechanical Systems and Signal Processing. 2018;103:39-59.

14. Sikdar SK. Machinability of nickel based superalloys with carbide and ceramic tools in milling. [Dissertation]. Montreal: Concordia University; 2007.

15. Henderson AJ, Bunget C, Kurfess TR. Cutting force modeling when milling nickel-base superalloys. In: Proceedings of the ASME 2010 International Manufacturing Science and Engineering Conference; 2010 Oct 12-15; Erie, PA, USA. p. 193-202.

16. Li HZ, Zeng H, Chen XQ. An experimental study of tool wear and cutting force variation in the end milling of Inconel 718 with coated carbide inserts. Journal of Materials Processing Technology. 2006;180(1-3):296-304.

17. Krain HR, Sharman ARC, Ridgway K. Optimisation of tool life and productivity when end milling Inconel 718TM. Journal of Materials Processing Technology. 2007;189(1-3):153-161.

18. Yao C, Tan L, Yang P, Zhang D. Effects of tool orientation and surface curvature on surface integrity in ball end milling of TC17. International Journal of Advanced Manufacturing Technology. 2018;94(5-8):1699-1710.

19. Hao Z, Gao D, Fan Y, Han R. New observations on tool wear mechanism in dry machining Inconel 718. International Journal of Machine Tools and Manufacture. 2011;51(12):973-979.
20. Davoodi B, Eskandari B. Tool wear mechanisms and multiresponse optimization of tool life and volume of material removed in turning of $\mathrm{N}-155$ iron-nickel-base superalloy using RSM. Measurement. 2015;68:286-294.

21. Thakur A, Gangopadhyay S, Mohanty A. Investigation on Some Machinability Aspects of Inconel 825 During Dry Turning. Materials and Manufacturing Processes. 2015;30(8):1026-1034.

22. Zhu D, Zhang X, Ding H. Tool wear characteristics in machining of nickel-based superalloys. International Journal of Machine Tools and Manufacture. 2013;64:60-77.

23. Gaitonde VN, Karnik SR, Maciel CHA, Rubio JCC, Abrão AM. Machinability Evaluation in Hard Milling of AISI D2 Steel. Materials Research. 2016;19(2):360-369.

24. Shi Z, Li Y, Liu Z, Qiao Y. Determination of minimum uncut chip thickness during micro-end milling Inconel 718 with acoustic emission signals and FEM simulation. International Journal of Advanced Manufacturing Technology. 2017. DOI: 10.1007/s00170-017-0324-z.

25. Sonawane HA, Joshi SS. Analysis of machined surface quality in a single-pass of ball-end milling on Inconel 718. Journal of Manufacturing Processes. 2012;14(3):257-268.

26. Tazehkandi AH, Pilehvarian F, Davoodi B. Experimental investigation on removing cutting fluid from turning of Inconel 725 with coated carbide tools. Journal of Cleaner Production. 2014;80:271-281. 